\title{
Memory and resistance
}

Joseph DeLappe

This is the Author's version of the article:

DeLappe, J. (2019) Memory and resistance. Radical History Review, 2019(133).

The published version is available at:

https://doi.org/10.1215/01636545-7160150 
Introductory Text:

In all my work, the intent is to forge connections between concept, object, interaction and a questioning/critical stance regarding issues ranging from pure aestheticism to contemporary geopolitics. The theoretical basis for my work lies in the belief that it is essential, as an artist and citizen of the world, to engage in and challenge the norms and expectations of the digital present and the larger cultural context. I seek to forge connections, explore the thoughtful processing of information, and develop exigencies that inform, provoke and question.

Past projects and ongoing efforts share an approach to critical and conceptual positioning as an artist - developing works that inquisitively engage issues of memory, politics, militarism, history, physicality and the virtual. Throughout the work I seek to find a synthesis between conflicting processes and ideas: analog/digital, concept/happenstance, physical/virtual, politics/art - all with a dedicated consideration and questioning of contemporary technologies and artistic practice.

Bio:

Joseph DeLappe is an internationally recognized artist and activist working at the intersection of art, technology, social engagement and interventionist strategies exploring our geo-political contexts. Works in online gaming performance, public engagements, participatory sculpture and electromechanical installation have been shown throughout the United States and internationally. DeLappe lives in Scotland where he is the Professor of Games and Tactical Media at Abertay University in Dundee, Scotland. In 2017 he was awarded a Guggenheim Fellowship in the Fine Arts.

Abstract:

Joseph DeLappe's is a visual artist and activist, herein are images and texts detailing a diversity of creative projects and actions that function to challenge and question our militaristic context. Works in this feature explore the intersections of art, technology, social engagement and interventionist strategies. The included projects utilize digital processes, interruptive strategies and participatory processes as tools for political, social and creative transformation.

Descriptive texts for images

1) 1,000 Drones Image Nos: 1, 2, 6

The 1,000 Drones invites the public to create a small scale, papercraft replica of a General Atomics MQ-1 Predator UAV (Unmanned Arial Vehicle) - a drone. Participants are asked to write the name of a civilian drone casualty upon the wings of the aircraft. The 1,000 paper drones created for this installation were made over the past three months by local students and volunteers working through the FSU Department of Art. The names for the project are from known civilian casualties from Pakistan and Yemen. The names of civilian drone casualties from our wars in Afghanistan and Iraq does not exist - these victims are noted in this work as "unknown". 
The project is an adaptation of The 1,000 Cranes or "Senbazuru" tradition from Japan. This tradition holds that anyone who folds one thousand cranes will be granted a wish. Since World War II the tradition has been associated with the atomic attacks upon Nagasaki and Hiroshima the folding of the cranes has become a wish for peace. Through the act of participating in this work of creative remembrance, the intention is for we, as Americans, to recognize and remember those innocents killed in our ongoing Global War on Terror.

2) Drone Project Image Nos: 1, 2, 3, 5

A commissioned project by the Center for Creativity and the Arts as the Visiting Artist in Residence for 2014 at Fresno State University. DeLappe worked for 2+ weeks on campus with over 100 students, interns and local volunteers to create a full-to-scale sculptural reproduction of a MQ1 Predator drone. The work was a participatory memorial - constructed onsite and resulting in a final, performative event held on April 6th, to write the names of 334 civilian drone casualties from Pakistan upon the surface of the drone (written in English and Urdu) the names were as well read aloud. The drone has been installed as if it had crash landed on the site. The sculpture was created using a digital 3D file that was been processed using Pepakura Designer and adapted for large-scale construction using low-res polygons for yellow corrugated plastic.

\section{3) Activist Rubber Stamp Started Kit Image Nos: 1, 2, 3}

Three rubber stamps that have been shared widely across the USA and abroad to allow participants to imprint politically oriented imagery upon their currency. These projects began first with the "In Drones We Trust", wherein nearly 3,000 stamps are were created and are in the hands of volunteers who have been stamping a tiny image of an MQ1 Predator Drone on their cash. The second stamp, "Hands Up Don't Shoot!" was inspired by the now iconic image of the protests and unrest surrounding the extrajudicial killings of African American males by US police forces. The third, "Sea Level Rising" involves stamping a rising sea level line to represent the threat of climate change and rising seas. DeLappe invited participants in the project to each send in at least one image of a stamped bill, noting location and date where the bill was stamped and put back into circulation.

4) Thrift Drones Image Nos: 1, 2

Purchased thrift store artworks are changed with the subtle addition of cut out images of Predator and Reaper drones. The work reimagines discarded, everyday paintings, prints and photographs as visual reminders of droned skies. These works have been widely shared using social media, primarily Instagram, Facebook and Twitter. To date DeLappe has made well over a 200 "Thrift Drones" - the first iteration of these works were featured salon style in 2017 at soloexhibition at the Sonoma Valley Museum of Art. There were a total of 120 "Thrift Drones" featured in this exhibition.

Since moving to Scotland in 2017, DeLappe continues this work, developing a UK based version of the project creating close to 100 new pieces so far. As the project moves forward, the intent is to strategically re-donate the droned artworks back to thrift stores and second hand shops in 
order to facilitate the public re-distribution of the works. The artist sees this as a long term effort to place drones into the skies of hundreds of pieces of thrift store art, document, share, exhibit, donate and so on.

5) Paper Soldier Image Nos: 1, 3

Created from 3D data directly extracted from the "America's Army Game" this depiction of my fallen avatar was realized utilizing Pepakura Designer papercraft techniques adapted for large scale. The figure is slighty larger than life size - the paper surface is covered with the printed list of names of US military casualties as used for the online intervention dead-in-iraq.

6) America's Army Action Figure Image Nos: 2, 4

In support of the America's Army Game, the Defense Department released a series of four AA "action figures" designated as "Real Heroes". I combined two of the actions figures through model building techniques to create a realistic depiction of an action figure, using as a reference, a screenshot of my fallen avatar as documented during my performative intervention, dead-in-iraq, 2006-2011

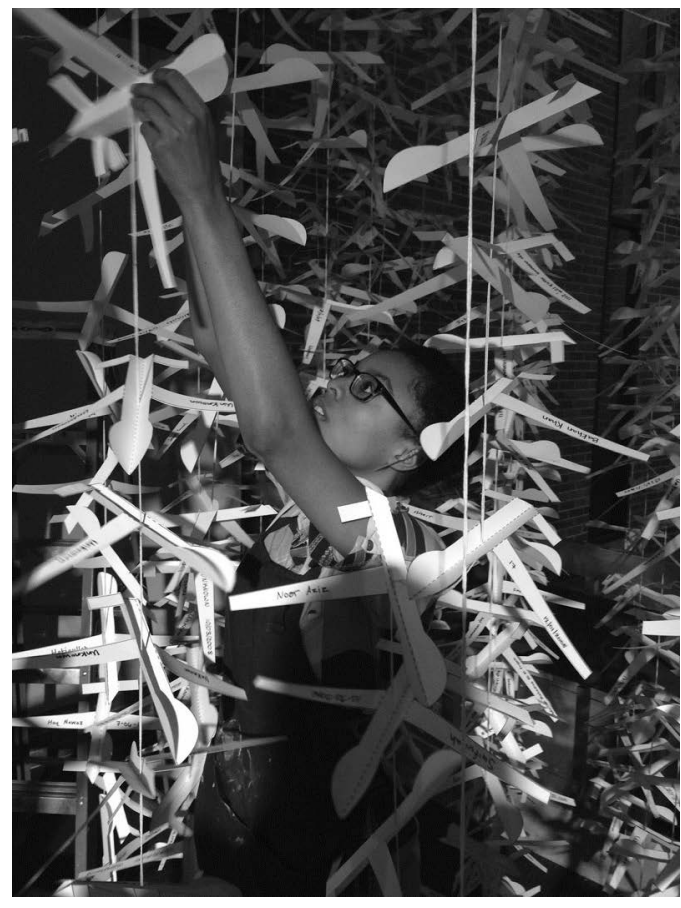

Figure 1. 1,000 Drones No.1. Image courtesy of the artist

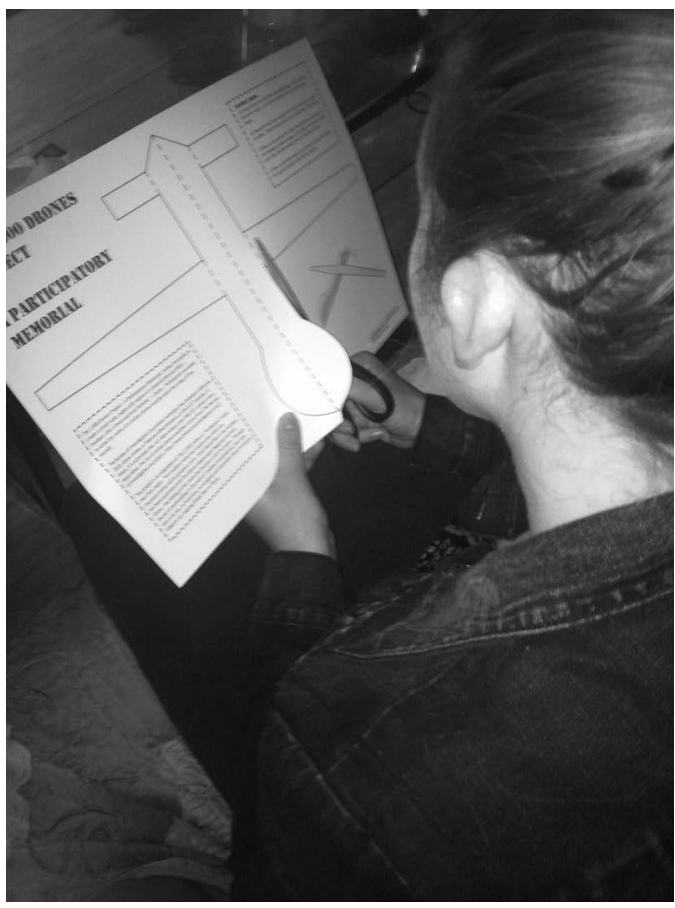

Figure 2. 1,000 Drones No.6. Image courtesy of the artist 


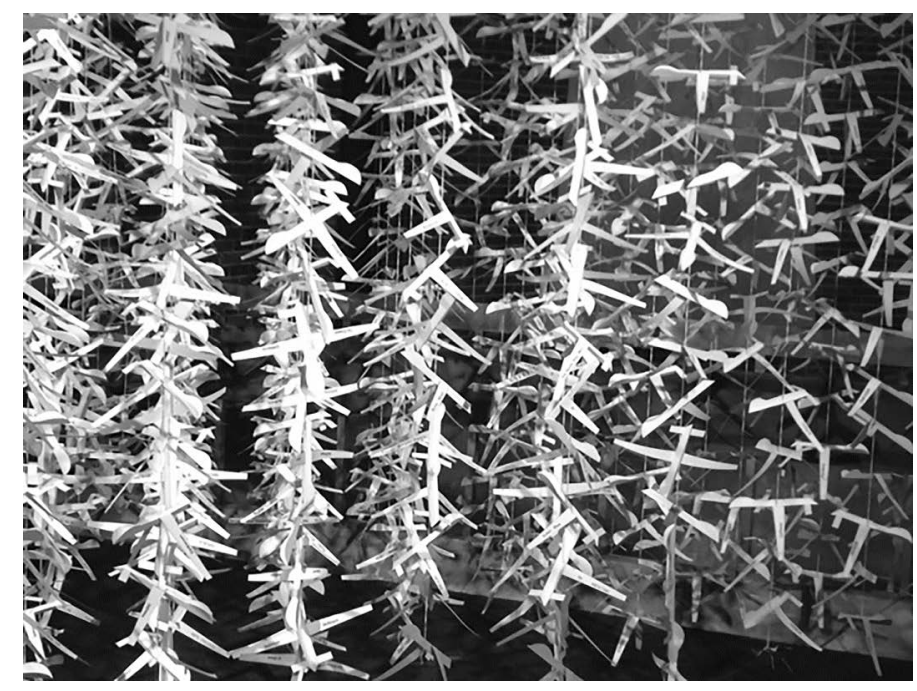

Figure 3. 1,000 Drones No.2. Image courtesy of the artist

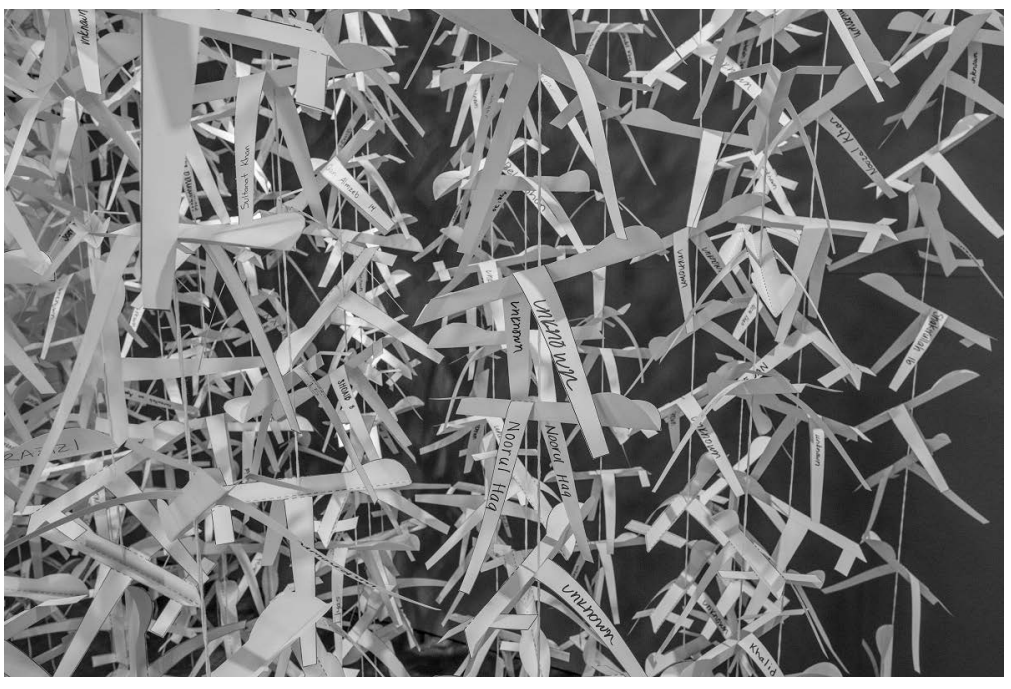

Figure 4. 1,000 Drones. Photo by Robert Holmes. Image courtesy of the artist

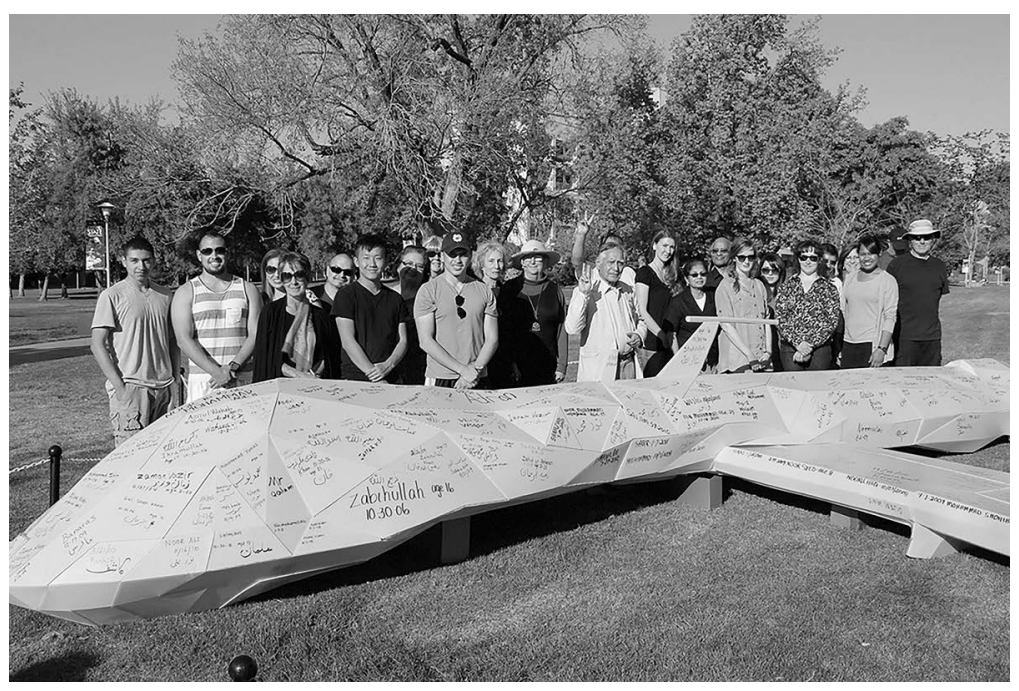

Figure 5. Drone Project No.1. Image courtesy of the artist

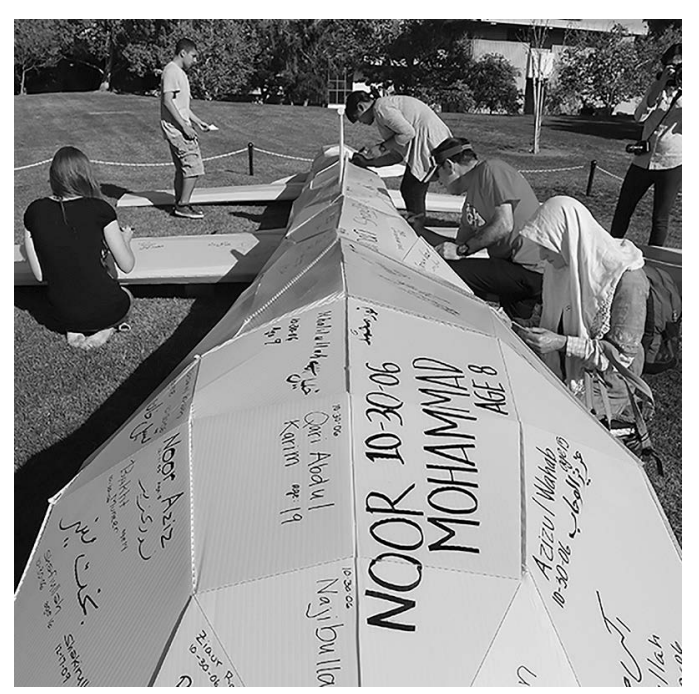

Figure 6. Drone Project No.2. Image courtesy of the artist 


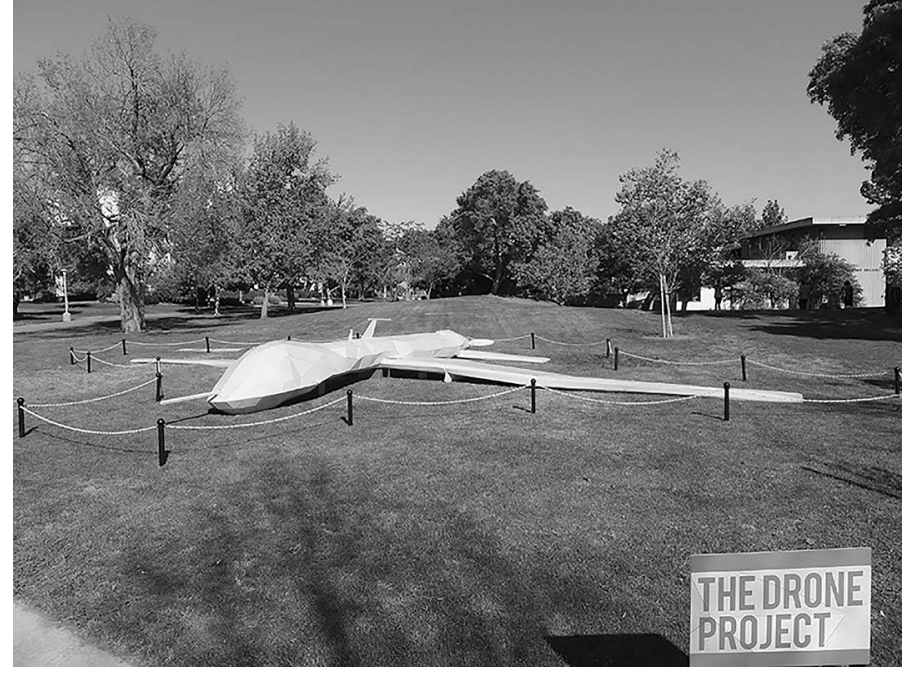

Figure 7. Drone Project No.3. Image courtesy of the artist

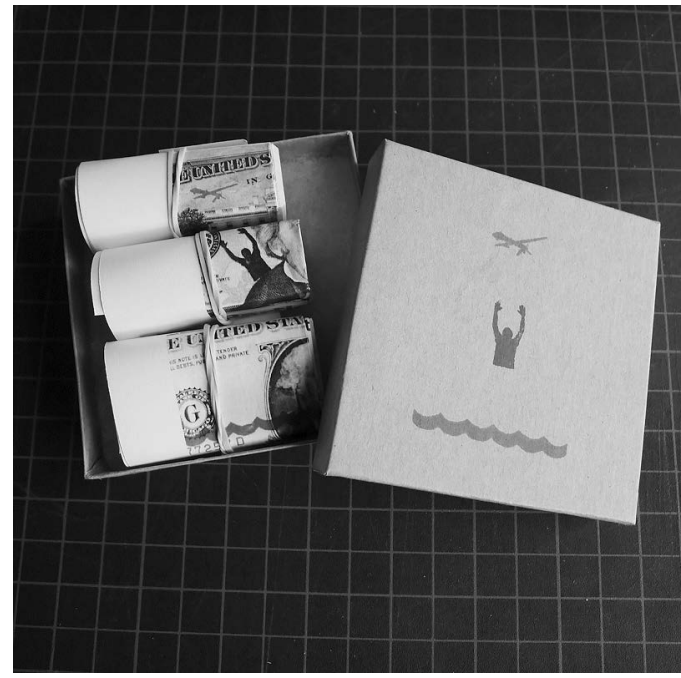

Figure 9. Activist Rubber Stamp Starter Kit No.1. Image courtesy of the artist

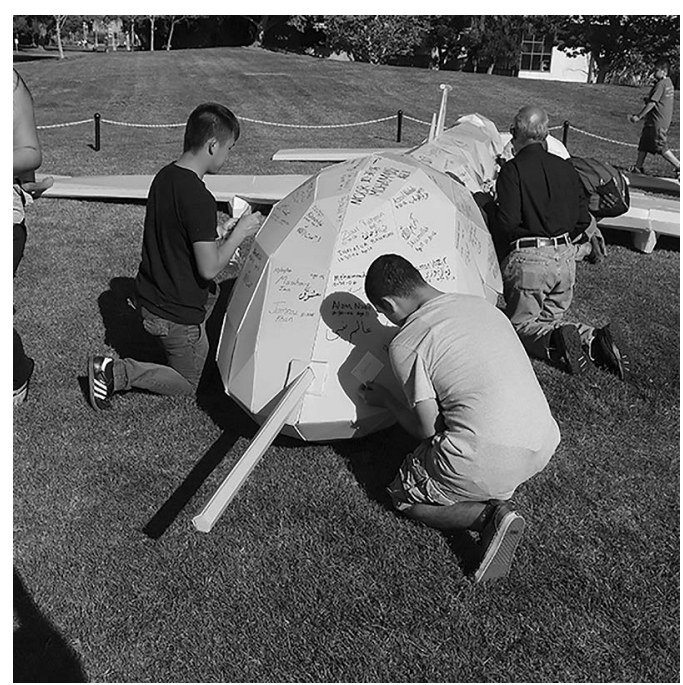

Figure 8. Drone Project No.5. Image courtesy of the artist

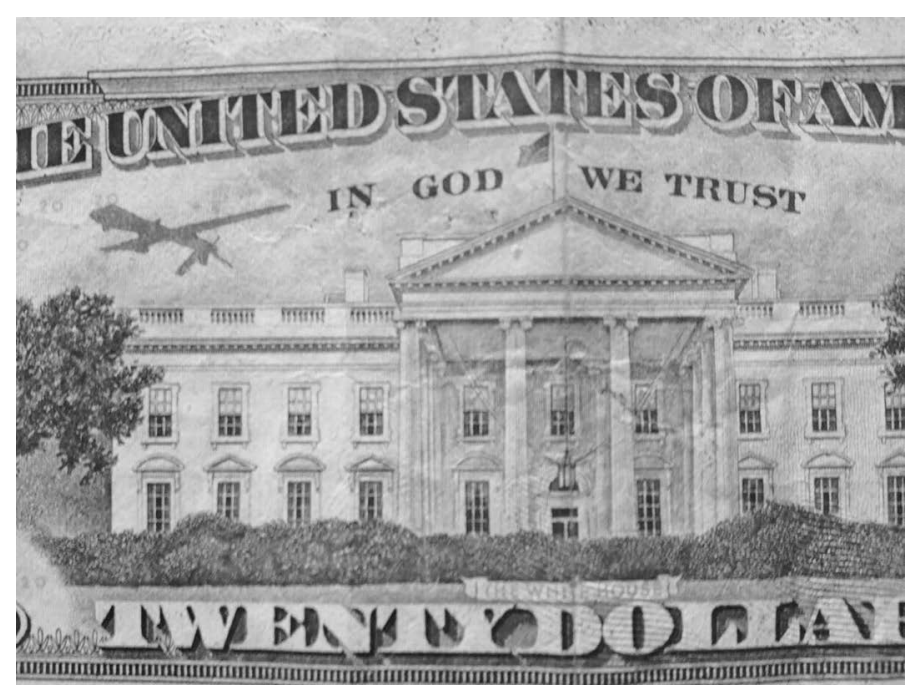

Figure 10. Rubber Stamp No.2: In Drones We Trust, 2014. Image courtesy of the artist 


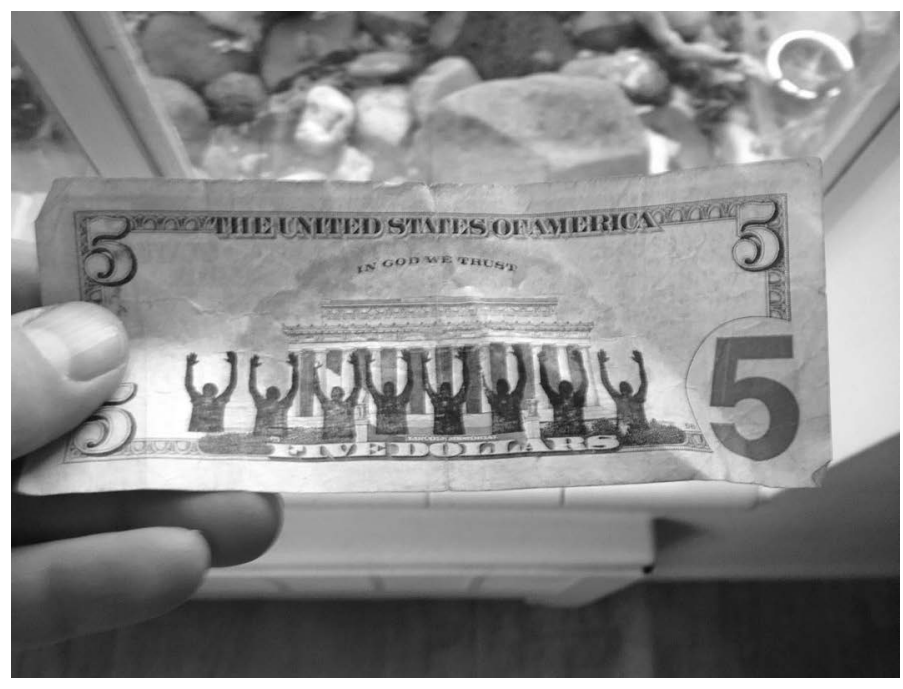

Figure 11. Rubber Stamp No.3: Hands Up Don't Shoot!, 2014-15. Image courtesy of the artist

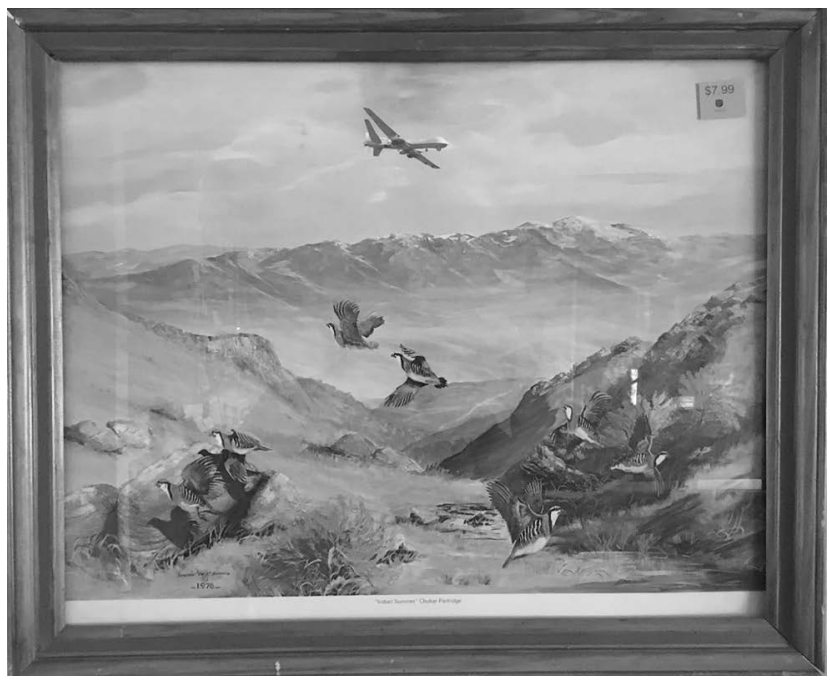

Figure 13. Thrift Drones No.2. Image courtesy of the artist

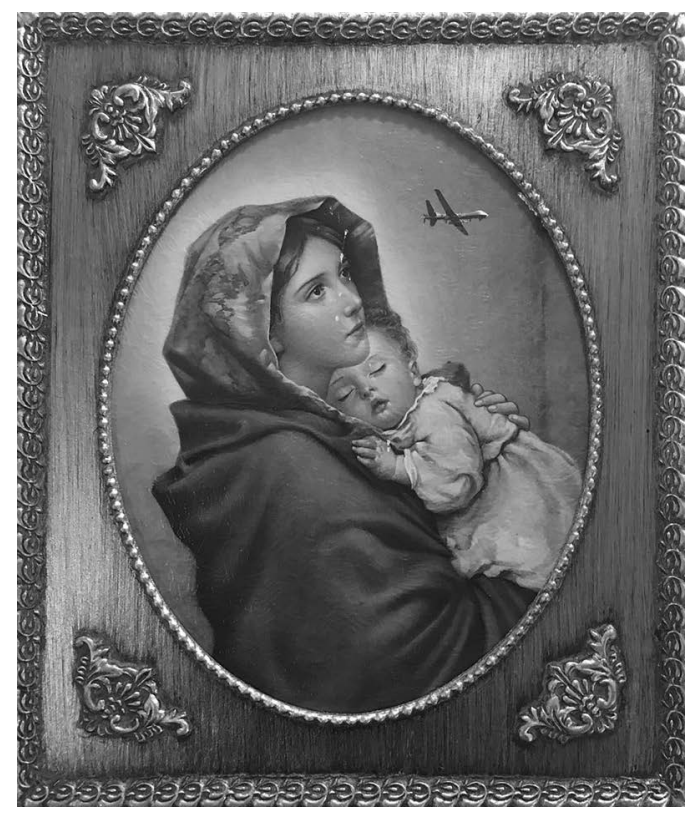

Figure 12. Thrift Drones No.1. Image courtesy of the artist

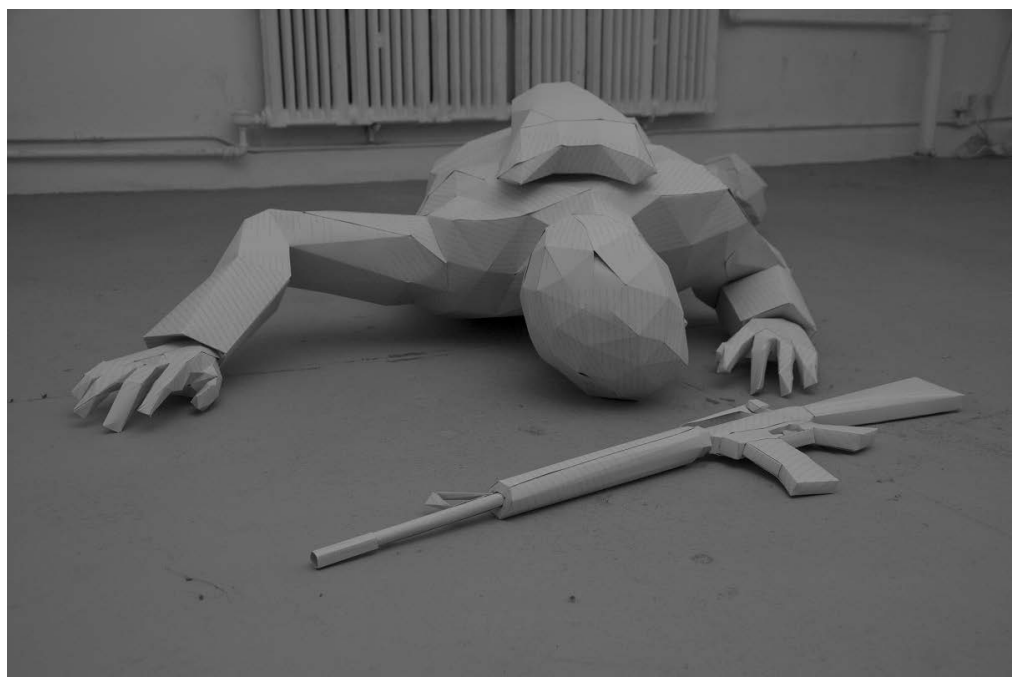

Figure 14. Paper Soldier No.1. Image courtesy of the artist. Photo by Christine A. Butler 


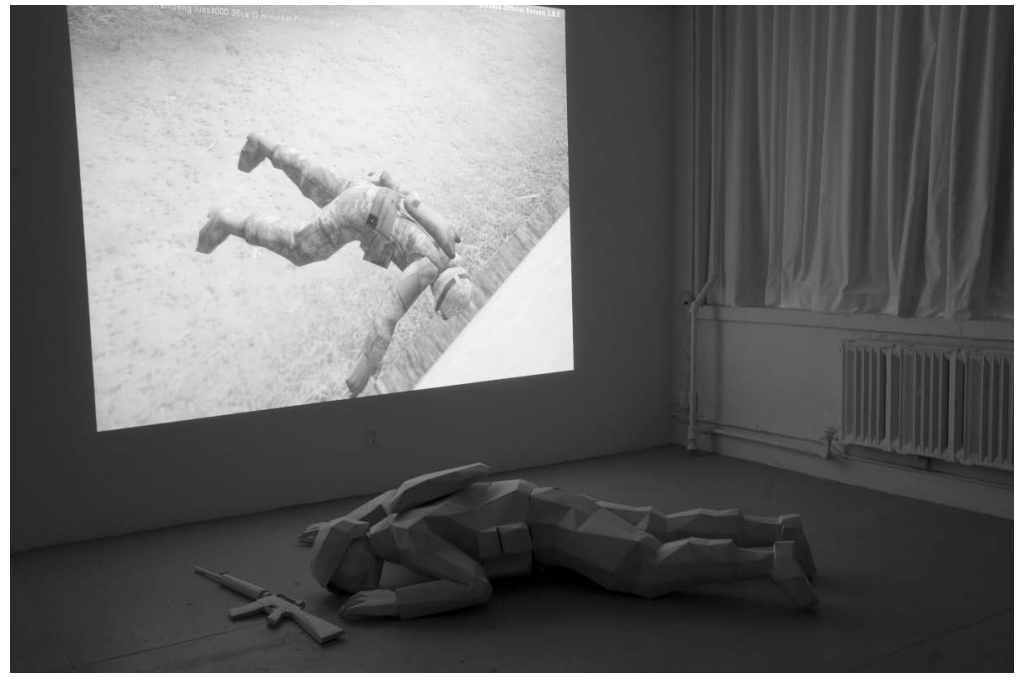

Figure 15. Paper Soldier No.3. Image courtesy of the artist. Photo by Christine A. Butler

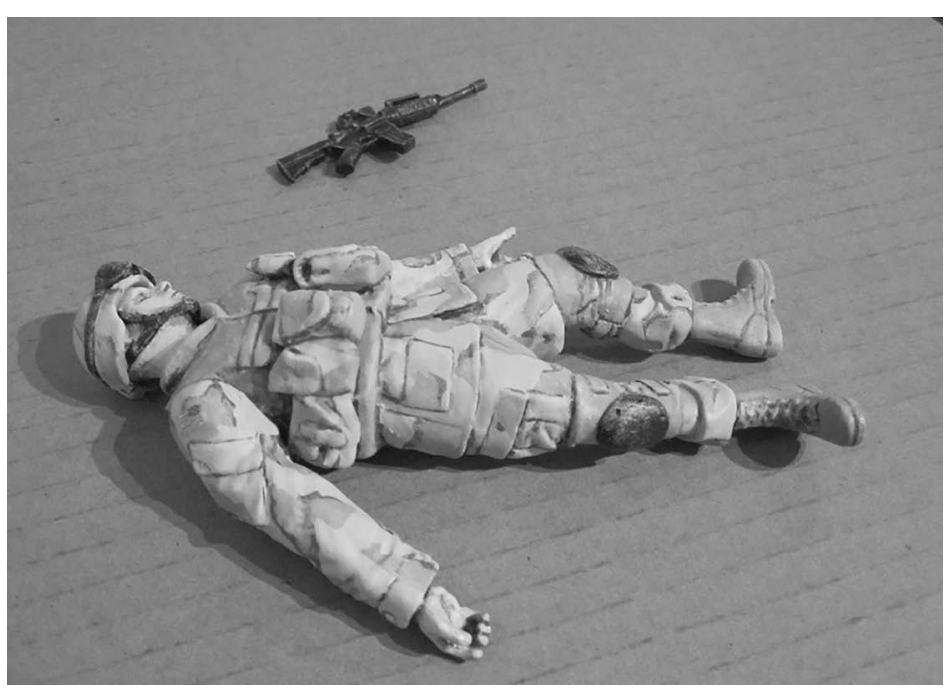

Figure 16. America's Army Action Figure No.2. Image courtesy of the artist

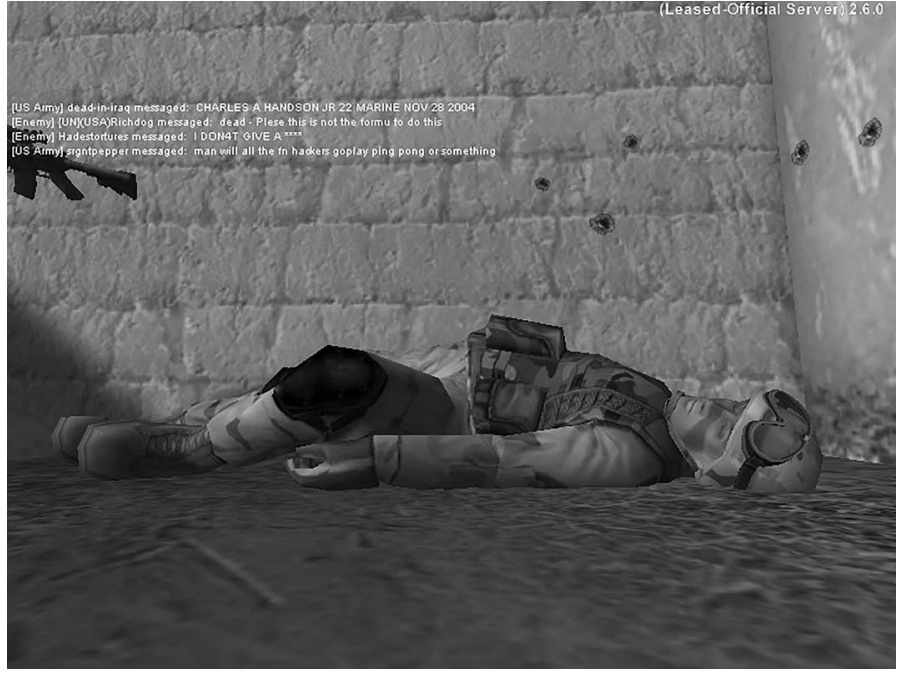

Figure 17. America's Army Action Figure No.4. Image courtesy of the artist 